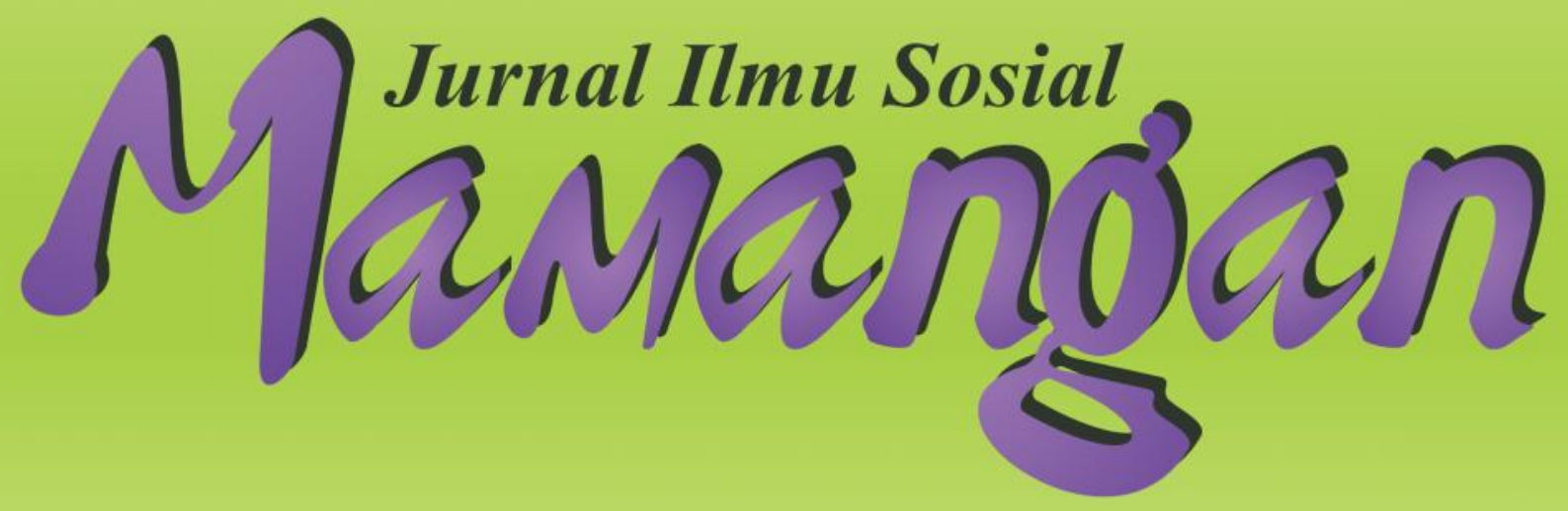

Efektifitas Program Keluarga Harapan (PKH) Dalam Upaya Pengentasan Kemiskinan Di Nagari Lagan Hilir, Kab. Pesisir selatan Apando Ekardo, Firdaus \& Nilda Elfemi

Pelaksanaan Program Corporate Social Responsibility (CSR) PT. VUM (Visi Utama Mandiri)

Yesi Herlina, Dian Anggraini Oktavia \& Elvawati

Sosial Ekonomi Perempuan Migran Kembali (Return Migrant) Jorong Kapuh, Nagari Sumani, Kab. Solok

Yuliana Nengrum, Yulkardi, Darmairal Rahmad

Pengemis Anak Di Pasar Raya Padang, Sumatera Barat

Mira Dona Eka Putri, Yulkardi \& Nilda Elfemi

Buruh Tani Jemputan Di Desa Sako Dua, Kec. Kayu Aro Barat, Kab. Kerinci

Wibi Wijaya, Zusmelia \& Elvawati

Konflik Pengelolaan Parkir Liar Di Pantai Purus, Kec. Padang Barat, Kota Padang

IImiati Amril, Ardi Abbas \& Surya Prahara 


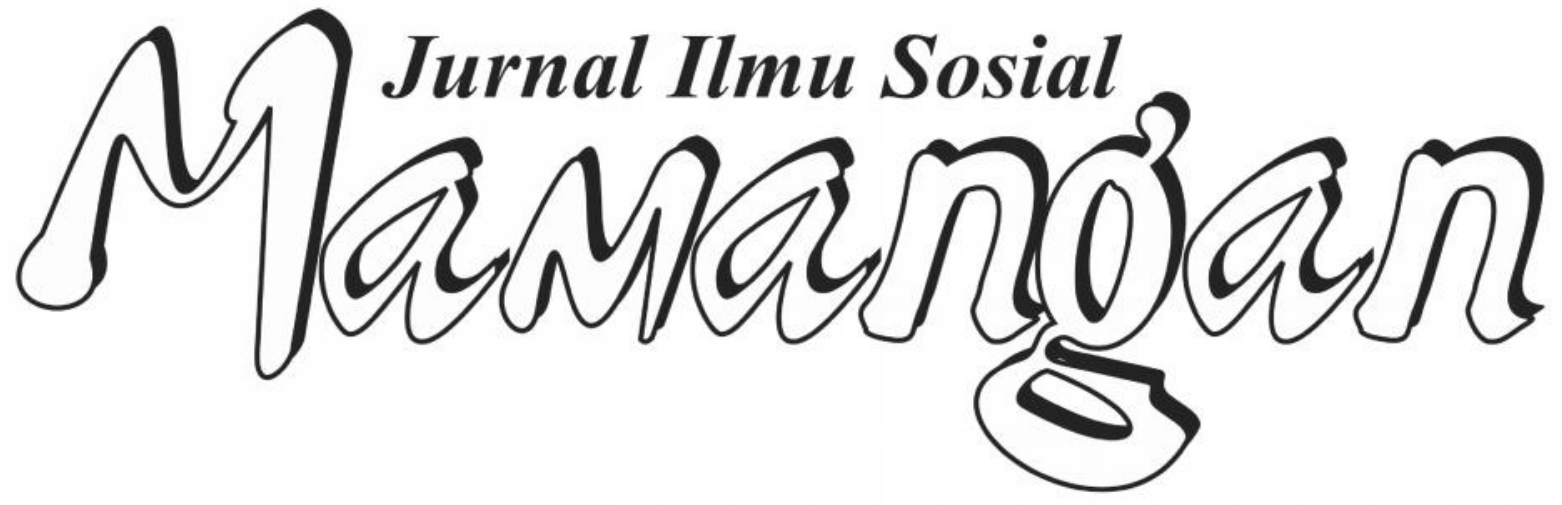




\section{Mitra Bestari}

Prof. Dr. Afrizal, MA. (FISIP, Unand Padang)

Dr. A. Latief Wiyata, M. Si. (Universitas Jember, Jember)

Prof. Dr. Badaruddin, M. Si. (FISIP, USU Medan)

Dr. Fikarwin Zuska, M. Si. (FISIP, USU Medan)

Nurus Shalihin, M. Si., Ph.D. (Fak. Ushuluddin IAIN Imam Bonjol Padang)

Dr. Semiarto A. Purwanto, M. Si. (FISIP, UI Jakarta)

Dr. Wahyu Wibowo, M. Si. (Universitas Nasional, Jakarta)

\section{Dewan Redaksi}

Dr. Zusmelia, M. Si.

Dr. Maihasni, M. Si.

Firdaus, S. Sos., M. Si.

\section{Pemimpin Redaksi}

Firdaus, S. Sos., M. Si.

\section{Anggota Redaksi}

Dian Kurnia Anggreta, S. Sos., M. Si.

Rinel Fitlayeni, S. Sos., MA.

Rio Tutri, M.Si.

Sri Rahayu, M. Pd.

Surya Prahara, SH.

Yuhelna, MA

ISSN: 2301-8496

Alamat Redaksi:

Laboratorium Program Studi Pendidikan Sosiologi, STKIP PGRI Sumbar Kampus STKIP PGRI, Jl. Gunung Pangilun, Padang, Sumatera Barat

Email: redaksimamangan@yahoo.com \& daus_gila @yahoo.com

Penerbit :

Program Studi Pendidikan Sosiologi, STKIP PGRI Padang 


\section{DAFTAR ISI}

Efektifitas Program Keluarga Harapan (PKH) Dalam Upaya Pengentasan Kemiskinan Di Nagari Lagan Hilir, Kab. Pesisir selatan

Apando Ekardo, Firdaus \& Nilda Elfemi ..

Pelaksanaan Program Corporate Social Responsibility (CSR) PT. VUM

Yesi Herlina, Dian Anggraini Oktavia \& Elvawati

Sosial Ekonomi Perempuan Migran Kembali (Return Migrant) Jorong Kapuh, Nagari Sumani, Kab. Solok

Yuliana Nengrum, Yulkardi, Darmairal Rahmad

Pengemis Anak Di Pasar Raya Padang, Sumatera Barat

Mira Dona Eka Putri, Yulkardi \& Nilda Elfemi

Buruh Tani Jemputan Di Desa Sako Dua, Kec. Kayu Aro Barat, Kab. Kerinci

Wibi Wijaya, Zusmelia \& Elvawati.

Konflik Pengelolaan Parkir Liar Di Pantai Purus, Kec. Padang Barat, Kota Padang

Ilmiati Amril, Ardi Abbas \& Surya Prahara

$40-48$ 


\title{
PELAKSANAAN PROGRAM CORPORATE SOCIAL RESPONSIBILITY (CSR) PT. VISI UTAMA MANDIRI (VUM) DI JORONG SUNGAI KUNYIT, KAB. SOLOK SELATAN
}

\author{
Yesi Herlina, Dian Anggraini Oktavia \& Elvawati \\ Sekolah Tinggi Keguruan dan Ilmu Pendidikan (STKIP) PGRI Sumatera Barat
}

\begin{abstract}
This article talks about Corporate Social Responsibility (CSR) PT. Visi Utama Mandir (PT. VUM). The company is engaged in mining iron ore. This article describes the company's CSR programs implemented, and to describe the impact of CSR programs to the community Jorong Koto Sungai Kunyit subdistrict Sangir Balai Janggo. The approach used in this study is a qualitative approach and descriptive. Determination of informants done Snowbolling Sampling. Collect data through interviews, observation and document study. The results showed that the company's CSR prorgam: the first, physical program, which the company provided assistance to the opening of new roads, road repair help communities, disaster relief, assistance for sports facilities, places of worship aid, and assistance every month. Second, non-physical program: health education and entrepreneurship training. Help the opening of new roads, easier access to public transportation. Help community road improvement, repair roads damaged in a residential area residents Jorong Koto Sungai Kunyit, to meet the public demand for transportation smoothly. Disaster relief, PT. VUM provide assistance such as: issuing machine, giving money, giving them the tools kitchen utensils, and others. Sporting equipments, awarded when a proper sports venues to be renovated in order to better the welfare of society. Help places of worship, giving donations and assistance to local houses of worship, with the aim of increasing public worship and religious knowledge. Help regularly every month, every month the implementation of assistance is provided to all households in Jorong Turmeric and Jorong Koto Sungai Sungai Sungkai, to help meet the basic needs of society
\end{abstract}

\section{Keyword : CSR Impact, CSR Companies, Mining Companies}

\begin{abstract}
ABSTRAK
Tulisan ini mengulas tentang program Corporate Social Responsibility (CSR) PT.VUM. Perusahaan ini bergerak dalam bidang tambang biji besi. Artikel ini mendeskripsikan program CSR yang dilaksanakan perusahaan, serta mendeskripsikan dampak program CSR kepada masyarakat Jorong Koto Sungai Kunyit Kecamatan Sangir Balai Janggo. Pendekatan penelitian yang digunakan adalah pendekatan kualitatif dengan tipe deskriptif. Penentuan informan dilakukan secara Snowbolling Sampling. Cara mengumpulkan data dengan wawancara, observasi dan studi dokumen. Hasil penelitian menunjukkan prorgam CSR yang dilakukan perusahaan ada dua;pertama, program fisik, dimana perusahaan memberi bantuan untuk pembukaan jalan baru, bantuan perbaikan jalan masyarakat, bantuan bencana, bantuan untuk sarana olahraga, bantuan tempat ibadah, dan bantuan rutin setiap bulan. Kedua, program non fisik yaitu: penyuluhan kesehatan dan pelatihan kewirausahaan. Bantuan pembukaan jalan baru, mempermudah akses transportasi masyarakat. Bantuan perbaikan jalan masyarakat, perbaikan jalan yang rusak di daerah perumahan warga Jorong Koto Sungai Kunyit dan jalan sekitar Nagari Sungai Kunyit, untuk memenuhi kebutuhan masyarakat terhadap transportasi yang lancar. Bantuan bencana,
\end{abstract}


PT. VUM memberi bantuan seperti: mengeluarkan alat berat, memberi uang, memberi alat perkakas dapur, dan lain-lain. Bantuan sarana olahraga, diberikan apabila tempat-tempat olahraga semestinya untuk direnovasi agar kesejahteraan masyarakat lebih baik. Bantuan tempat ibadah, memberikan sumbangan serta bantuan kepada rumah ibadah setempat, dengan tujuan meningkatkan ibadah dan pengetahuan agama masyarakat. Bantuan rutin setiap bulan, penerapan bantuan rutin setiap bulan ini diberikan kepada seluruh KK yang ada di Jorong Koto Sungai Kunyit dan Jorong Sungai Sungkai, untuk membantu pemenuhan kebutuhan pokok masyarakat.

\section{Kata Kunci : Dampak CSR, CSR Perusahaan, Perusahaan Tambang}

\section{PENDAHULUAN}

Tanggung jawab sosial perusahaan atau yang dikenal dengan Corporate Social Responsibility (CSR) bukan sekedar trend social, namun merupakan sinergi dari upaya yang berkelanjutan untuk menginformasi program-program sosial demi menciptakan ekonomi yang lebih ramah lingkungan dengan melibatkan para pelaku pembangunan untuk bekerjasama dalam perlindungan dan pengelolaan lingkungan hidup. Program ini disusun dengan tujuan memberikan panduan melaksanakan kegiatan Corporate Social Responsibility (CSR) khususnya di bidang lingkungan. Panduan ini juga ditunjukkan kepada pemerintah pusat maupun daerah agar dipergunakan sebagai program dalam membantu perusahaan melaksanakan kegiatan CSR (Hatta 2011).

Menurut Schermerhorn Corporate Social Responsibility (CSR) sebagai suatu kepedulian organisasi bisnis untuk bertindak dengan cara-cara mereka sendiri dalam melayani kepentingan organisasi dan kepentingan publik eksternal. CSR adalah sebuah pendekatan dimana perusahaan mengintegrasikan kepedulian sosial dalam operasi bisnis mereka dan dalam interaksi mereka dengan para pemangku kepentingan (stakeholder) berdasarkan prinsip kesukarelaan dan kemitraan (Kidzie 2011). Menurut Kicullen dan Kooistra Corporate Social Responsibility (CSR) adalah tingkatan pertanggungjawaban moral yang dianggap berasal dari perusahaan di luar kepatuhan terhadap hukum Negara. Menurut Fraderick et al Corporate Social Responsibility (CSR) dapat diartikan sebagai prinsip yang menerangkan bahwa perusahaan harus dapat bertanggungjawab terhadap efek yang berasal dari setiap tindakan di dalam masyarakat maupun lingkungannya (Crowher 2008).

CSR merupakan bentuk nyata kepedulian kalangan dunia usaha terhadap lingkungan di sekitarnya. Kegiatan CSR ini dilakukan diberbagai bidang, mulai dari pendidikan, kesehatan, ekonomi, lingkungan bahkan sosial budaya. Konsep CSR sebagai bentuk tanggung jawab sosial perusahaan sudah mulai dikenal semenjak tahun 1970an, namun mulai berkembang pesat di Indonesia sejak tahun 2000. Kegiatan CSR baru bisa berkelanjutan jika program yang dibuat oleh perusahaan benar-benar merupakan komitmen bersama dari segenap unsur yang ada di dalam perusahaan. Tanpa adanya dukungan semua elemen, maka program CSR tersebut seolah hanya merupakan bentuk kepedulian dari pemegang saham belaka. Sementara diyakini bahwa melakukan kegiatan CSR yang berkelanjutan akan memberikan dampak positif dan manfaat yang lebih besar, baik bagi perusahaan maupun stakeholder yang terkait sekaligus dapat menciptakan kehidupan masyarakat yang lebih mandiri dan sejahtera (Assad 2012).

Undang-undang tentang CSR di Indonesia tertuang dalam UU PT No. 40 tahun 2007 pasal 74 ayat 1 yaitu perseroan yang menjalankan kegiatan usahanya dibidang dan atau berkaitan dengan sumber daya alam wajib melaksanakan tanggung jawab sosial (CSR) dan lingkungannya, perseroan yang tidak melaksanakan kewajiban dikenai sanksi sesuai dengan ketentuan peraturan perundang-undangan. Peraturan lain yang menyentuh CSR adalah UU No.25 Tahun 2007 tentang Penanaman Modal. Pasal 15 (b) menyatakan bahwa "Setiap penanam modal berkewajiban melaksanakan tanggung jawab sosial 
perusahaan." Meskipun UU ini telah mengatur sanksi-sanksi secara terperinci terhadap badan usaha atau usaha perseorangan yang mengabaikan CSR pasal 16 ayat $d$ mengatakan setiap penanaman modal bertanggung jawab menjaga kelestarian lingkungan. Artinya perusahaan penanaman modal berkewajiban memprogramkan kegiatan CSR sehingga dapat meningkatkan jaminan kelangsungan aktivitas perusahaan karena ada nya hubungan yang serasi dan saling ketergantungan antara pengusaha dan masyarakat.

Perusahaan yang melaksanakan program CSR diantaranya terdapat di Jorong Koto Sungai Kunyit terdapat perusahaan PT. VUM. Tujuan dari program CSR tersebut untuk mensejahterakan masyarakat Jorong Koto Sungai kunyit. Sehingga dalam tulisan ini mendeskripsikan program CSR yang dilaksanakan oleh PT. VUM, serta dampak program tersebut bagi masyarakat.

\section{TINJAUAN PUSTAKA}

Penelitian seputar tanggung jawab perusahaan kepada masyarakat atau dalam tulisan ini disebut program CSR, dan CSR internal telah dilakukan sebelumnya. Seperti tulis Munthe, 2008, dengan judul penelitian Tanggung Jawab Sosial Perusahaan Terhadap Kesejahteraan Karyawan (Studi Kasus di PT. Perkebunan Nusantara IV Persero Medan) di Medan. Tulisan ini mengulas aktivitas PT. Perkebunan Nusantara IV melaksanakan tanggungjawab sosial perusahaan, terhadap kesejahteraan karyawan atau biasa juga disebut dengan Corporate Social Responsibility (CSR) internal. Aktifitas CSR internal pada perusahaan ini sudah baik. Hal ini terlihat dari interaksi dan komunikasi baik antara karyawan dan pihak manajemen terjalin harmonis dimana karyawan sebagai mitra dapat bekerja dengan baik. Pihak manajemen juga memperhatikan kesejahteraan karyawan seperti adanya peningkatan upah berdasarkan golongan, adanya jaminan sosial bagi tenaga kerja, dimana seluruh karyawan masuk dalam program jamsostek, fasilitas kesehatan, dan keselamatan kerja. Disamping itu PT. Perkebunan Nusantara IV, mempunyai klinik sendiri yang sudah cukup memadai. Perusahaan juga memberikan berbagai tunjangan, dan bonus bagi karyawan. PT. Perkebunan Nusantara IV telah memenuhi hak-hak yang dibutuhkan oleh karyawan sesuai dengan perundangan ketenagakerjaan Indonesia (Munthe 2008).

CSR yang diberikan kepada masyarakat pernah diteliti oleh Siregar, 2007, yang berjudul Analisis Sosiologis Terhadap Implementasi Corporate Social Responsibility (CSR) Pada Masyarakat Indonesia. Hasil analisis yang didapat bahwa Implementasi program Corporate Social Responsibility perusahaan tidak tepat sasaran sehingga perlu melibatkan peran mahasiswa dalam pelaksanaan program Corporate Social Responsibility (Siregar 2007). Yang membedakan penelitian terdahulu dengan tulisan ini adalah bahwa sebelumnya, Munthe (2008) membahas CSR perusahaan, yang fokus untuk mensejahterakan karyawan-karyawan, Siregar (2007) fokus kepada perusahaan melibatkan mahasiswa dalam penerapan program Corporate Social Responsibility (CSR) sedangkan tulisan ini fokus pada CSR yang digunakan perusahaan untuk mensejahterakan masyarakat.

\section{METODE PENELITIAN}

Pendekatan penelitian yang dilakukan adalah pendekatan kualitatif dengan tipe penelitian deskriptif. Pengumpulan data dilakukan dengan observasi non partisipan. Dalam penelitian ini, penulis mendatangi lokasi, kemudian melakukan pencatatan seputar perihal yang diamati, seperti aktivitas perusahaan memberikan CSR, interaksi pihak perusahaan dengan masyarakat. Wawancara juga dilakukan untuk mengumpulkan data, pihak yang diwawancarai diantaranya masyarakat yang tinggal disekitar perusahaan dan mahasiswa penerima dampak CSR, pihak perusahaan. Wawancara diakhiri apabila data yang dikumpulkan tersebut telah menunjukkan hasil yang sama dengan informan sebelumnya, maka kegiatan wawancara tidak perlu dilanjutkan. Proses wawancara berjalan lancar karena informan menerima kedatangan peneliti dengan baik. Adapun data yang diperoleh dari informan adalah program CSR dan dampak pelaksanaan program CSR. Selain itu juga dilakukan studi dokumen. Dimana dikumpulkan dokumen 
berupa dokumen tertulis dan foto-foto kegiatan CSR yang pernah dilakukan PT. VUM, kepada masyarakat Jorong Koto Sungai Kunyit.

\section{PROGRAM CSR PT. VUM}

PT. VUM (Visi Utama Mandiri), merupakan perusahaan tambang, yang menghasilkan galian Bijih Besi. Perusahaan ini terletak di Sungai Kunyit Kecamatan Sangir Balai Janggo Kabupaten Solok Selatan Sumatera Barat. Luas area pertambangan perusahaan ini adalah 2.936 ha. Perkiraan cadangan Bijih Besi sesuai estimasi manajemen diperkirakan sekitar 5,463 juta metrik ton (mt). Perusaan ini berada dalam pengawasan dan bimbingan Supervisor Produksi Bijih Besi.

Program CSR dilakukan perusahaan merupakan wujud pertanggungjawaban setiap perusahaan atau instansi kepada lingkungan masyarakat setempat, bisa diketahui pada salah satu perusahaan yaitu PT. VUM yang berada di Jorong Koto Sungai Kunyit, Kabupaten Solok Selatan memiliki program CSR, bentuk program ada dua yaitu program fisik dan program non fisik terhadap masyarakat Jorong Koto Sungai Kunyit diantaranya sebagai berikut:

\section{Bantuan Pembukaan Jalan Baru}

ProgramCSR perusahaan pertama yang dilakukan yaitu memberi bantuan untuk pembukaan jalan baru pada tahun 2009. Jalan ini sebagai telah ada, kemudian dibantu oleh perusahaan dengan program CSR. Setelah pekerjaan pembukaan jalan baru tersebut dilakukan, akhirnya harapan masyarakat Jorong Koto Sungai Kunyit itu terwujud, memudahkan transportasi masyarakat dalam mengangkut hasil perkebunan.

Pembukaan jalan baru ini disamping untuk memperlancar transportasi juga akan berdampak kepada peningkatan ekonomi masyarakat, kalau selama ini membawa hasil perkebunan dengan jarak yang jauh dan kendaraanpun sulit untuk melewatinya maka sekarang sudah bisa dibawa dengan mobil. Waktu tempuh juga semakin cepat.

Selama tahun 2009 sampai 2013, terdapat 5 jalan yang dibantu pembangunannya oleh perusahaan. Untuk lebih jelasnya dapat dilihat pada tabel berikut:.

\section{Tabel 1}

Daftar Jalan yang Dibantu

Pembangunannya oleh PT. VUM

\begin{tabular}{|c|l|c|c|}
\hline No & Lokasi & Tahun & $\begin{array}{l}\text { Jmlh } \\
\text { (km) }\end{array}$ \\
\hline 1 & $\begin{array}{l}\text { Jalan ke ladang } \\
\text { masyarakat dekat PT. } \\
\text { VUM }\end{array}$ & 2009 & 1,5 \\
\hline 2 & $\begin{array}{l}\text { Jalan ke ladang } \\
\text { masyarakat arah barat } \\
\text { pabrik }\end{array}$ & 2010 & 15 \\
\hline 3 & $\begin{array}{l}\text { Jalan menuju plasma } \\
\text { masyarakat }\end{array}$ & 2011 & 13 \\
\hline 4 & $\begin{array}{l}\text { Jalan ke ladang } \\
\text { masyarakat arah utara PT. } \\
\text { VUM }\end{array}$ & 2012 & 17 \\
\hline 5 & $\begin{array}{l}\text { Jalan ke ladang } \\
\text { masyarakat yang masih } \\
\text { belum bisa dilewati } \\
\text { kendaraan }\end{array}$ & 2013 & 10 \\
\hline & \multicolumn{2}{|c|}{ Total } & $\mathbf{5 6 , 5}$ \\
\hline
\end{tabular}

Dari tabel di atas dapat dilihat bahwa ada 5 jalan yang dibuka baru oleh PT.VUM dengan total jarak 56,5 km. Dengan dibukanya jalan baru ini setiap tahunnya ada perubahan setiap jalan yang dibuka oleh PT. VUM. Maka dari itu masyarakat harus bisa untuk selalu memelihara jalan yang sudah dibuka ini, sebab kalau tidak dipelihara dengan baik maka jalan ini tidak akan bertahan lama, dengan harapan kedepannya akan bisa ditingkatkan untuk pengaspalan, semuanya ini sangat tergantung dari perencanaan program CSR PT. VUM.

Melalui program CSR PT. VUM ini masyarakat sekitar lokasi perusahaan bisa merasakan danpak pembukaan jalan baru. Bentuk bantuan pembukaan jalan baru ini hanya dilakukan ke jalan ladang-ladang masyarakat yang ada disekitar lingkungan perusahaan seperti jalan yang menuju ke ladang masyarakat yang bersebelahan dengan perusahaan tersebut. Dengan adanya program CSR ini memudahkan masyarakat menuju ladang sehingga aktivitas masyarakat sekitar berjalan lancar.

\section{Bantuan Perbaikan Jalan Masyarakat}

Bantuan jalan Jorong Koto Sungai Kunyit Nagari Sungai Kunyit Kecamatan Sangir Balai Janggo sebenarnya sudah pernah diperbaiki oleh pemerintah, karena usianya yang sudah tua dan digunakan 
sebagai jalan utama Perusahaan Biji Besi dan Perusahaan Sawit, sehingga kondisi jalan tersebut pada akhirnya menjadi rusak. Ada dua kemungkinan yang dialami, jika ingin ke Nagari Sungai Kunyit Kecamatan Sangir Balai Janggo yaitu kendaraan akan berlumuran lumpur atau menghirup debu jalan.

Oleh sebab itu CSR PT. VUM memberi bantuan perbaikan jalan. Bantuan perbaikan jalan baik itu jalan yang ada di Jorong Koto Sungai Kunyit ataupun di Jorong lain, memperlancar aktifitas masyarakat. Terdapat 4 jalan yang diperbaiki oleh PT. VUM dengan CSR mereka, tertera dalam tabel berikut:

Tabel 2

Daftar Jalan yang Diperbaiki PT. VUM

\begin{tabular}{|c|l|}
\hline No & \multicolumn{1}{|c|}{$\begin{array}{l}\text { Bentuk perbaikan jalan yang } \\
\text { dilakukan oleh PT. VUM }\end{array}$} \\
\hline 1 & $\begin{array}{l}\text { Pengerasan jalan plasma masyarakat } \\
\text { Jorong Sungai Kunyit }\end{array}$ \\
\hline 2 & $\begin{array}{l}\text { Penimbunan jalan yang } \\
\text { menghubungkan jalan Sungai Kunyit- } \\
\text { Lubuk Malako berupa timbunan } \\
\text { dengan pasir dan batu }\end{array}$ \\
\hline 3 & Perbaikan jalan ke Jorong lain \\
\hline 4 & $\begin{array}{l}\text { Perbaikan jalan sekitar Jorong Koto } \\
\text { Sungai Kunyit }\end{array}$ \\
\hline
\end{tabular}

Dari tabel di atas dijelaskan bentuk perbaikan jalan mulai dari perbaikan, penimbunan, sampai pengerasan jalan yang telah dilakukan oleh PT. VUM, itu semua bentuk dari tanggungjawab sebuah perusahaan kepada lingkungan sekitar. Perbaikan jalan ini tidak hanya di Jorong Koto Sungai Kunyit saja tetapi Jorong lain juga mendapat bantuan perbaikan jalan dari perusahaan.Dengan adanya bantuan perbaikan jalan masyarakat tersebut, yang awalnya jalan itu memang sudah rusak juga ditambah dengan adanya mobil pembawa Bijih Besi dan Sawit berjalan setiap harinya sehingga mengakibatkan jalan semakin rusak, sekarang sudah ada perubahan meskipun belum diperbaiki secara maksimal. Bantuan perbaikan jalan baik itu untuk Jorong Koto Sungai Kunyit maupun untuk Jorong lain aktifitas dan perjalanan masyarakat tidak terganggu lagi dan masyarakat sudah mendapatkan apa yang diharapkan dari sebuah tanggungjawab perusahaan kepada daerah tersebut.

\section{Bantuan Bencana}

Bencana suatu kejadian yang berlaku secara terkejut, bersifat kompleks dan mengakibatkan kehilangan nyawa, kemusnahan kepada harta benda atau alam sekitar serta memberhentikan aktivitas masyarakat setempat.Kejadian ini memerlukan pengendalian yang melibatkan sumber, peralatan, dan tenaga manusia yang saling membantu sesama warga setempat.Bencana ini juga tidak menjejaskan aktivitas harian penduduk setempat secara meluas.Pihak perangkat daerah mempunyai kemampuan untuk mengawal dan meminta pertolongan.

PT. VUM memberikan bantuan kepada korban bencana kebakaran di rumah warga penduduk Jorong Koto Sungai Kunyit, bantuan tersebut langsung diserahkan oleh Humas dan Supervisor PT. VUM pada hari kejadian tersebut. Bantuan yang diberikan kepada korban antara lain berupa perlengkapan dapur, tikar, mengeluarkan alat berat, dan lain-lain. Bantuan bencana yang sudah diberi oleh PT. VUM berjalan dari tahun 2013. Bencana yang dialami masyarakat yaitu kebakaran. Aktif melakukan berbagai kegiatan sosial sebagai bentuk tanggungjawab sosialnya atau Corporate Social Responsibility (CSR).

Keterangan informan menyatakan kalau program CSR PT. VUM tentang bantuan bencana sudah dilakukan atau diterapkan kepada masyarakat Jorong Koto Sungai Kunyit. Bantuan bencana ini bisa bermacam-macam yang diberikan oleh PT. VUM seperti, bantuan alat dapur, mengeluarkan alat berat, memberi uang, dan lain-lain yang bisa digunakan oleh keluarga korban untuk keperluan selama aktifitas sehari-hari belum bisa dikerjakan seperti biasanya karena sibuk untuk menyiapkan dari hasil bencana.

\section{Bantuan Untuk Sarana Olahraga}

PT. VUM juga berpartisipasi dalam membantu pembangunan di lingkungan perusahaan, khususnya yang berkaitan langsung dengan kepentingan masyarakat seperti bantuan sarana dan pemeliharaan fasilitas umum, bantuan fasilitas dan perlengkapan olahraga khususnya pemuda 
untuk mendorong pada kegiatan positif dan bermanfaat bagi warga sekitar.

$$
\text { Jorong Koto Sungai Kunyit }
$$

mendapatkan bantuan dana untuk pembangunan sarana olahraga dari PT. VUM, tujuan bantuan ini untuk meningkatkan kualitas sarana olahraga, pemberian dana ini juga diberikan langsung oleh Humas PT. VUM kepada karang taruna. Bantuan yang diberikan ini bisa digunakan untuk membeli alat atau bahan baku untuk merenovasi pembangunan dan pengembangan sarana olahraga. Sarana olahraga yang akan diwujudkan adalah lapangan Bola Kaki, lapangan Bulutangkis, dan lapangan Bola Volli. Sarana olahraga ini untuk meningkatkan kreatifitas dan aktifitas para pecinta olahraga sehingga masyarakat sekitar bisa menyelesaikan sarana olahraga tersebut dengan cepat agar suasana pemain dan penonton nyaman ditempat area lapangan olahraga. Pandangan masyarakat terhadap adanya bantuan dari PT. VUM tentang dana sarana olahraga yang diberikan, menyambut positif. Disamping sarana olahraga yang harus diperbaiki dan direnovasi karena sudah tua, ini juga wujud kepedulian perusahaan kepada masyarakat. Dengan adanya sarana olahraga di Jorong Koto Sungai Kunyit bisa untuk menambah aktifitas sore harinya bagi masyarakat yang hobi berolahraga dan jika pembangunan atau tempat olahraga terawat dan terjaga maka masyarakatpun akan senang untuk menikmati suasana keolahragaannya.

\section{Bantuan Tempat Ibadah}

Sebagai wujud kepeduliannya terhadap masyarakat sekitarnya, PT. VUM juga menyerahkan bantuan untuk pengembangan sarana ibadah yang ada di Sungai Kunyit, dimana setiap tempat ibadah yang ada di daerah tersebut mendapatkankan bantuan dari PT. VUM. Bantuan ini merupakan bagian dari program Corporate Social Responsibility (CSR) perusahaan, sebagai wujud kepedulian PT. VUM pada lingkungan sekitarnya, terutama di Jorong Koto Sungai Kunyit. Program CSR pembangunan tempat ibadah telah mulai tahun 2009. Bantuan diberikan dengan tujuan untuk meningkatkan fasilitas peribadatan pada daerah lingkungan sehingga masyarakat dapat meningkatkan pemahaman dan pengamalan ibadah dengan baik.Bantuan yang diberikan dalam bentuk bantuan sarana dan fasilitas ibadah, serta bantuan kegiatan keagamaan. Saat lebaran hajipun perusahaan memberikan bantuan hewan qurban.

\section{Bantuan Rutin}

Program CSR PT. VUM tidak hanya terbatas pada bantuan musibah atau bencana, perbaikan dan pembukaan jalan baru, dan lain-lain, tetapi juga meliputi program seperti setiap bulannya secara rutin mentransfer uang kepada setiap KK yang ada di Jorong Koto Sungai Kunyit dan Jorong Sungai Sungkai. Bantuan rutin setiap bulan ini diberikan kepada setiap KK yang ada di 2 Jorong yaitu Jorong Koto Sungai Kunyit dan Jorong Sungai Sungkai. Dalam program tersebut perusahaan mengeluarkan dana setiap bulannya untuk 223 KK di Jorong Koto Sungai Kunyit dan 200 KK untuk masyarakat Jorong Sungai Sungkai. Bantuan ini merupakan fee yang diberikan perusahaan kepada masyarakat, atas aktivitas tambang. Tidak hanya masyarakat yang memperoleh, ninik mamak, organisasi masyarakat pun mempolorehnya. Untuk lebih jelas dapat dilihat pada tabel berikut:

\section{Tabel 3}

Daftar fee Diberikan PT. VUM kepada Masyarakat

\begin{tabular}{|c|l|c|}
\hline No & Pihak Penerima & Persentase \\
\hline 1 & Masyarakat & $25 \%$ \\
\hline 2 & Ninik Mamak & $20 \%$ \\
\hline 3 & Katang Taruna & $10 \%$ \\
\hline 4 & PKK & $10 \%$ \\
\hline 5 & Penggunaan Ulayat & $10 \%$ \\
\hline 6 & Kegiatan Keagamaan & $10 \%$ \\
\hline 7 & Penemu & $5 \%$ \\
\hline 8 & Tokoh Masyarakat & $5 \%$ \\
\hline
\end{tabular}

Fee yang dibayarkan sesuai dengan perjanjian awal yang dilakukan oleh perusahaan dengan masyarakat. Untuk KK yang menerima bantuan masing-masing memperoleh Rp 700.000 per bulannya. Bantuanuang setiap bulan yang diberikan kepada masyarakat membantu ekonomi masyarakat. 


\section{Penyuluhan Kesehatan}

Program CSR PT. VUM tidak hanya dalam bentuk fisik saja tetapi ada juga dalam bentuk non fisik yaitu salah satunya penyuluhan kesehatan, penyuluhan kesehatan dapat dilakukan dengan cara menyebarkan pesan kepada masyarakat seputar kesehatan. Jenis kegiatannya yang telah dilakukan diantaranya penyuluhan kesehatan, penyediaan pelayanan kesehatan masyarakat, kesehatan lingkungan dan pembiayaan kesehatan secara mandiri.

Penyuluhan kesehatan mencakup individu, keluarga, kelompok dan masyarakat. Penyuluhan kesehatan pada individu dapat dilakukan di rumah sakit, puskesmas, dan posyandu.PT. VUM memberikan penyuluhan kesehatan kepada masyarakat ini supaya masyarakat sekitar peduli kesehatan. Kegiatan dilakukan setiap tiga bulan sekali, dengan mendatangkan dokter dan tenaga medis lainnya.

\section{Pelatihan Kewirausahaan}

Perusahaan juga pernah melaksanakan kegiatan pelatihan kewirausahaan. Pelatihan kewirausahaan ini bertujuan agar masyarakat sekitar bisa meliki suatu usaha atau bisnis dengan baik sehingga dengan apa yang didapat saat adanya pelatihan kewirausahaan masyarakat bisa mengembangkan usanya dengan baik. Masyarakat mengikuti pelatihan ini tidak banyak hanya orang-orang yang berkeinginan untuk melakukan usaha maka mereka mau mengikuti pelatihan kewirausahaan. Pelatihan kewirausahaan dimulai denga mengenalkan jenis usaha yang dapat dilakukan oleh masyarakat. Sehingga dapat memperbaiki perekonomian.

\section{DAMPAK PROGRAM CSR PT. VUM}

Penerapan CSR memiliki dampak terhadap masyarakat Jorong Koto Sungai Kunyit. Dampak dari pembukaan jalan baru adalah memudahkan masyarakat. Sebelum dilakukan pembukaan jalan, beberapa wilayah sulit untuk ditempuh baik itu dengan berjalan kaki atau memakai kendaraan sehingga. Pelaksanaan pembukaan jalan baru ini berubah setiap tahunnya atau tahun sekarang lebih sedikit pembukaan jalannya dibanding tahun sebelumnya. Hal ini terjadi karena sudah bertahap dilakukan pembangunan jalan. Pembukaan jalan baru menuju ke ladang milik masyarakat sangat membantu masyarakat. Hal ini dikarenakan dapat memudahkan masyarakat untuk berangkat kerja keladang. Bahkan dengan dibuka jalan, masyarakat keladang sudah bisa menggunakan kendaraan, dan mempermudah mengangkut hasil pertanian. Pembangunan jalan baru ini juga memberi peluang kerja bagi masyarakat. Karena dalam pembangunan jalan tersebut dilibatkan masyarakat.

Proses pembangunan jalan baru ini tidak sepenuhnya dilakukan atas inisiatif pihak perusahaan. Berdasarkan asil penelitian, pembukaan jalan diusulkan oleh masyarakat. Usulan tersebut disampaikan agar pihak perusahaan bersedia membantu. Pertimbangan usulan berdasarkan agar semakin mudah akses masyarakat keluarmasuk daerah Jorong Koto Sungai Kunyit, mmudahkan akses masyarakat ke lahan pertanian dan kebun-kebu plasma milik petani.

Bantuan bencana ini dapat diberikan kepada masyarakat yang dilakukan perusahaan seperti saat terjadi bencana yang dialami masyarakat. Masyarakat yang menjadi korban bencana merasa terbantu. Pihak PT. VUM langsung tulun kelapangan memantau lokasi terjadi kebakaran. Konrban kebakaran juga diberikan bantuan sejumlah RP 25.000.000 guna membangun kembali rumah korban yang terkena bencana.

\section{KESIMPULAN}

Program Corporate Social Responsibility (CSR) PT. VUM ada dua program yaitu program fisik dan program non fisik. Program fisik yaitu: bantuan untuk pembukaan jalan baru, bantuan perbaikan jalan masyarakat, bantuan bencana, bantuan untuk sarana olahraga, bantuan tempat ibadah, dan bantuan rutin setiap bulan. Program non fisik yaitu: penyuluhan kesehatan dan pelatihan kewirausahaan. Bantuan yang diberikan dalam program CSR ini memang sangat membantu masyarakat. Namun dalam pelaksanaan program terdapat keluhan yang dirasakan masyarakat, seperti saat diberikan bantuan uang tunai tiap bulannya, terdapat variasi jumlah uang yang diterima masyarakat. 
Tulisan ini memang masih belum menggali lebih mendalam, persoalan pemberian fee dari perusahaan kepada masyarakat. Pemberian fee ini berkaitan dengan penggunaan lahan untuk aktifitas industri. Tulisan yang membahas penggunaan lahan untuk kegiatan industri pernah diulas dalam tulisan yang berjudul Kontestasi Ruang; Tinjauan Sosiologis Terhadap Keadilan Ekologis, dimana saat mendapat ketidak adilan masyarakat akan melakukan resistensi dan perlawanan dalam mempertahankan atau merebut tanah mereka (Afrizal 2012). Sehingga dirasa perlu dikaji lebih mendalam, kenapa setiap bulannya PT. VUM membayar fee kepada masyarakat. Dalam proses penelitian ditemukan pernyataan kurang berkenan masyarakat terhahadap pemberian fee yang dirasa kurang merata. Dalam Kondisi ini masyarakat memang memiliki hak mendapat fee sesuai dengan kesepakatan awal, namun disisi lain, ini merupakan wujud katup penyelamat agar tidak terjadi konflik antara masyarakat dengan perusahaan. Karena penelitian konflik masyarakat dengan perusahaan telah banyak ditulis. Seperti perjuanganan komunitas petani menuntut ganti rugi atas dugaan pencemaran lahan pertanian akibat limbah galian $\mathrm{C}$ masuk kelahan pertanian masyarakat (Anggreta 2012). Semoga letupan yang disampaikan masyarakat tidak meluas yang membuat hubungan perusahaan dan masyarakat relatif baik, karena banyaknya bantuan yag diberikan dengan program CSR.

\section{DAFTAR PUSTAKA}

Afrizal. 2012. "Kontestasi Ruang; Tinjauan Sosiologis Terhadap Keadilan Ekologis." Jurnal Ilmu Sosial Mamangan 1(1):1-9.

Anggreta, Dian Kurnia. 2012. "Perjuangan Hak Ekonogis Komunitas Petani." Jurnal Ilmu Sosial Mamangan 1(1):5159.

Assad, Ilyas. 2012. Petunjuk Pelaksanaan CSR Bidang Lingkungan. Jakarta: Kementerian Lingkungan Hidup.

Crowher, Dapit. 2008. Corporate Social Responsibility. Bandung: Alfabeta.

Hatta, Gusti Muhammad. 2011. Pedoman CSR Bidang Lingkungan. Jakarta: Kementerian Lingkungan Hidup.

Kidzie, Ulzi. 2011. "Corporate Social Responsibility (CSR) Menurut Perspektif Sosiologi."

Munthe, Krisma. 2008. "Tanggung Jawab Sosial Perusahan Terhadap Kesejahteraan Karyawan (Studi Kasus Di PT. Perkebunan Nusantara IV Persero Medan)." Universitas Sumatera Utara.

Siregar, Chairil N. 2007. "Analisis Sosiologis Terhadap Implementasi Corporate Social Responsibility Pada Masyarakat Indonesia." Institut Tekhnologi Bandung. 


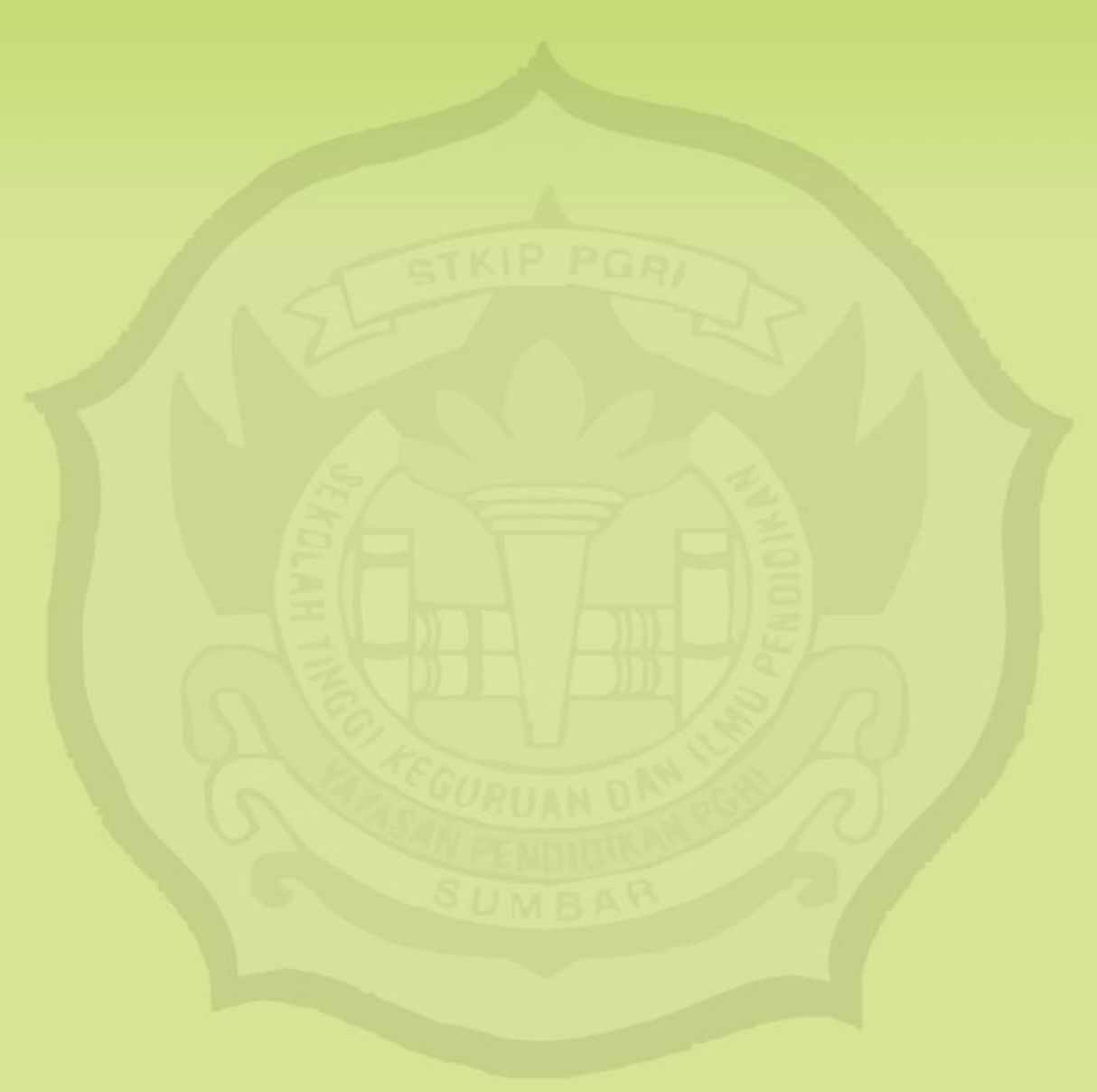

